\title{
Histamine reactivity during the refractory period after exercise induced asthma
}

\author{
ALLAN G HAHN, STEPHEN G NOGRADY, DOUGLAS McA TUMILTY, \\ STEVEN R LAWRENCE, ALAN R MORTON
}

From the Centre for Sports Studies, Canberra College of Advanced Education, Belconnen; the Respiratory Unit, Royal Canberra Hospital, Acton; the Sports Science Laboratory, Australian Institute of Sport, Bruce; and the Department of Human Movement and Recreation Studies, University of Western Australia, Nedlands, WA, Australia

ABSTRACT An episode of exercise induced asthma will usually be followed by a period during which further exercise will not induce asthma. Postulated mechanisms include persistence of catecholamines released during exercise, development of tolerance to released mediators, and mediator depletion. To investigate the underlying mechanism further eight asthmatic men underwent three experimental protocols as follows: two treadmill runs of eight minutes; two incremental challenges with histamine inhalation; and a treadmill run of eight minutes followed by an incremental challenge with histamine inhalation. In each case the two challenges began 40 minutes apart. Patients performed the paired exercise trial first. Refractoriness to bronchoconstriction was shown in the repeated exercise studies but did not occur with repeated histamine challenge. The geometric mean histamine concentrations required to produce a $20 \%$ fall in forced expiratory volume in one second $\left(\mathrm{FEV}_{1}\right)$ were $1.53 \mathrm{mg} / \mathrm{ml}$ and $0.93 \mathrm{mg} / \mathrm{ml}$ for the first and second challenges respectively (NS) and $1.4 \mathrm{mg} / \mathrm{ml}$ (NS) for the histamine challenge after exercise. It is concluded that refractoriness to exercise induced asthma is not explained by the development of smooth muscle tolerance to repeated histamine exposure or by the persistence of catecholamines released during exercise. The data are consistent with the theory of mediator depletion as the cause of refractoriness.

After an attack of exercise induced asthma, many asthmatic patients show a refractory period characterised by a substantially diminished bronchoconstrictive response to further exercise challenge..$^{1-3}$ For any individual the duration of this period appears to be directly proportional to the severity of the initial asthmatic episode and, in some cases, may exceed two hours. ${ }^{3}$

The existence of the refractory period after exercise induced asthma has generally been attributed to depletion of mediators stored in airway mast cells. ${ }^{2-4}$ An alternative suggestion is that there may be increased sympathoadrenal effects with repeated exercise. ${ }^{5}$ We reasoned that, if the first hypothesis were true, the sensitivity of subjects to inhaled his-

Address for reprint requests: Dr SG Nogrady, Respiratory Unit, Royal Canberra Hospital, Acton, ACT 2601, Australia.

Accepted 9 July 1984 tamine should remain unchanged during the refractory period. If refractoriness is due to accumulation of bronchodilating catecholamines persistence of these substances after an initial exercise test should afford some protection from the effects of histamine challenge. We therefore compared the response to inhaled histamine during the refractory period with the response in the absence of preceding exercise. We also examined the effect of repeated histamine provocation to exclude the development of smooth muscle tolerance to histamine as the mechanism of refractoriness.

\section{Methods}

Eight men (mean (SD) age 30.6 (9) years) gave their informed consent. All had a history of exercise induced asthma and showed a reduction of more than $15 \%$ in forced expiratory volume during the 919 
first second of exhalation $\left(\mathrm{FEV}_{1}\right)$ in response to a preliminary exercise test.

\section{PAIRED EXERCISE TEST}

Each subject initially performed two treadmill runs of eight minutes each separated by a recovery period of 32 minutes, the times being in keeping with the work of Schoeffel et al. ${ }^{4}$ The running speed was that which during preliminary tests produced a heart rate of $80-85 \%$ of the age predicted maximum. ${ }^{6}$ During exercise subjects breathed dry medical air from a Keogel $\mathrm{Y}$ valve connected to a balloon reservoir. The air was first cooled to below $-20^{\circ} \mathrm{C}$ by passage through a copper coil immersed in alcohol and dry ice, ensuring a moisture content of less than $1.07 \mathrm{mg} / \mathrm{l}^{7}$ Rewarming of the air before inhalation produced a mean (SD) inspiratory temperature of $11.7^{\circ}\left(2.9^{\circ}\right) \mathrm{C}$. In no subject did this temperature vary by more than $2^{\circ} \mathrm{C}$ between tests. Minute ventilation rates were recorded by a Hewlett Packard pneumotachograph in the inspiratory line. Expired air was passed through a 51 mixing box, from which samples were drawn during the final two minutes of each treadmill run. The samples were analysed for oxygen and carbon dioxide content (Morgan oxygen analyser model OA-500 and Morgan carbon dioxide analyser model 901-MK2), and oxygen uptakes were computed.

Temperatures of inspired and expired air were measured by standard thermistor probes (Yellow Springs Instruments, series 409-A) positioned $3.5 \mathrm{~cm}$ upstream and downstream from the oral cavity and connected to telethermometers (Yellow Springs Instruments, model 46 TUC). Respiratory heat exchange values were estimated for each minute of exercise using the formula of Deal et al. ${ }^{8}$ Dryness of the inspirate and full saturation of the expirate were assumed.

$\mathrm{FEV}_{1}$ was measured one minute before the start of the first of the paired exercise tests and immediately after its completion. Further measurements were taken after five, 10,15, 20, 28, and 31 minutes' recovery, the last recording representing the preexercise value for the second treadmill challenge. After the second challenge $F E V_{1}$ was measured at the same intervals except that observation was stopped after 20 minutes' recovery. All measurements were made with a Minato Autospirometer Model AS-700. Subjects were considered to have shown refractoriness if the percentage reduction in $\mathrm{FEV}_{1}$ from the immediate pre-exercise value was less than half as great for the second run as for the first. ${ }^{4}$

\section{DUAL HISTAMINE CHALLENGE}

On another day subjects underwent two challenges with histamine inhalation, each requiring adminis- tration of histamine in increasing concentrations $(0.03,0.06,0.125,0.25,0.5,1 \cdot 0,2 \cdot 0,4 \cdot 0,8 \cdot 0$, and $16.0 \mathrm{mg} / \mathrm{ml}$ ) until $\mathrm{FEV}_{1}$ fell by $20 \%$ from the preinhalation baseline. The second challenge began 40 minutes after the first. Histamine aerosols were generated by means of a Hudson nebuliser attached to a cylinder of medical air set at a flow rate of $81 / \mathrm{min}$. Subjects inhaled five inspiratory capacities of each concentration with 75 seconds between successive dosages. $\mathrm{FEV}_{1}$ was measured immediately before challenge and one minute after administration of each histamine dosage.

\section{ADMINISTRATION OF HISTAMINE AFTER EXERCISE}

On a separate occasion subjects completed an eight minute treadmill run followed 40 minutes later by a histamine inhalational challenge. Both challenges followed the protocols outlined above.

\section{STATISTICAL ANALYSIS}

The concentration of histamine causing a $20 \%$ fall in $\mathrm{FEV}_{1}\left(\mathrm{PC}_{20}\right)$ was obtained from individual dose response curves, and geometric mean values were calculated. Baseline and subsequent $\mathrm{FEV}_{1}$ values were compared by repeated measures analysis of variance followed where necessary by paired $t$ tests. The same techniques were used to compare oxygen uptake, minute ventilation, and respiratory heat loss during exercise. One way repeated measures analysis of variance was applied to the natural logarithms of $\mathrm{PC}_{20}$ values.

\section{Results}

\section{FACTORS INFLUENCING REPRODUCIBILITY OF} CHALLENGES

Mean $\mathrm{FEV}_{1}$ values recorded on arrival at the laboratory did not differ significantly between the three experimental protocols $(p>0.05)$. The two exercise tests constituting the first challenges of their respective paired sequences did not differ significantly $(p>0.05)$ in terms of oxygen uptake, $\Omega$ minute ventilation, or respiratory heat loss (table 1$)$. N The tests evoked very similar changes in $\mathrm{FEV}_{1}$, with maximum percentage falls virtually identical in seven of the eight subjects (mean (SD) values 43.2 $(12.7) \%$ and $42.7(10.7) \%$. The coefficient of variation ${ }^{9}$ was $6.6 \%$. Recovery was more rapid from histamine provocation than from exercise. Baseline

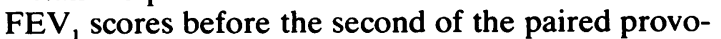
cations with histamine were therefore significantly higher than those for the challenge after exercise ( $p$ $<0.05$; table 2). 
Table 1 Mean values of oxygen uptake, total ventilation, and total respiratory heat loss for the three exercise challenges. (Differences did not reach significance $(p=0.05)$ on any occasion

\begin{tabular}{llccc}
\hline & & Run 1: paired exercise test & Run 2: paired exercise test & Run before histamine challenge \\
\hline Oxygen uptake (1/min) & Mean & 2.33 & 2.41 & 2.37 \\
Total ventilation (1 BTPS) & Mean & 07.54 & 0.56 & 0.60 \\
& SD & 139.6 & 473.0 & 456.0 \\
Total respiratory heat loss (kJ) Mean & 41.8 & 121.1 & 121.2 \\
& SD & 13.8 & 41.5 & 39.7 \\
\end{tabular}

Conversion: SI to traditional units-Heat loss: $1 \mathrm{~kJ} \approx 0.24 \mathrm{kCal}$. BTPS—body temperature, pressure and saturation.

\section{PAIRED EXERCISE CHALLENGE}

Maximum fall in $\mathrm{FEV}$, averaged $43 \cdot 2(12 \cdot 7) \%$ for the first run and $15 \cdot 7(9 \cdot 0) \%$ for the second (figure). According to the criterion employed, all eight subjects showed refractoriness. Mean pre-exercise $\mathrm{FEV}_{1}$ was significantly lower for the second treadmill run $(1.85(0.47) \mathrm{l})$ than for the first $(2.65$ $(0.55) \mathrm{l} ; \mathrm{p}<0.001)$. The immediate postexercise scores, however, were not significantly different ( $p$ $>0.05$ ), and the second run was associated with significantly higher values at five, 10, $15(p<0.05$ in each case), and $20(p<0.01)$ minutes of recovery (figure). This was despite close similarity of the two runs in terms of minute ventilation, respiratory heat loss, and oxygen uptake (table $1 ; \mathrm{p}>0.05$ ) by Student's $t$ test in each case).

\section{DUAL HISTAMINE CHALLENGE}

Table 2 shows the $\mathrm{PC}_{20}$ values for each subject. The geometric mean $\mathrm{PC}_{20}$ was $1.53 \mathrm{mg} / \mathrm{ml}$ for the first challenge and $0.93 \mathrm{mg} / \mathrm{ml}$ for the second. The difference was not significant ( $p>0.05)$. Of the eight subjects, five showed increased sensitivity to histamine in the second trial, two were less responsive, and one showed little change. Mean (SD) baseline FEV , was slightly higher for the first challenge $(2.50$ $(0.49) \mathrm{l})$ than for the second $(2.33(0.44) \mathrm{l})$, but the difference was not significant $(p>0 \cdot 05)$.
HISTAMINE CHALLENGE AFTER EXERCISE

For the histamine challenge after exercise the geometric mean $\mathrm{PC}_{20}$ was $1.4 \mathrm{mg} / \mathrm{ml}$. This was not significantly different from the corresponding values for the first and second stages of the dual histamine challenge ( $p>0.05$; table 2$)$.

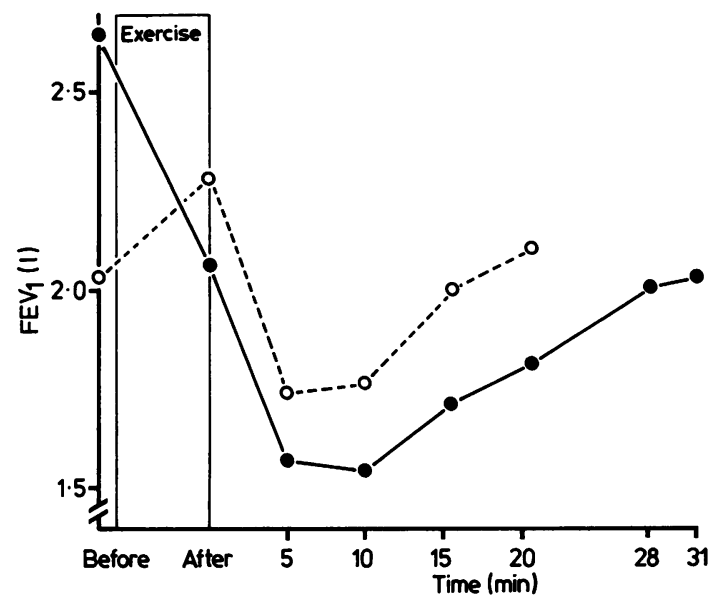

Mean forced expiratory volumes in one second $\left(F E V_{1}\right)$ in eight men with refractory asthma during a paired exercise test with two treadmill runs of eight minutes separated by an interval of 32 minutes. Figures on the horizontal axis indicate time after the end of exercise. ——Exercise 1; - - exercise 2.

Table 2 Prechallenge forced expiratory volumes in one second $\left(F E V_{1}\right)$ and histamine concentrations required to produce $20 \%$ fall in $F E V_{1}\left(P C_{20}\right)$ for the various challenges with histamine

\begin{tabular}{|c|c|c|c|c|c|c|}
\hline \multirow[t]{2}{*}{ Case No } & \multicolumn{2}{|c|}{ Dual histamine challenge I } & \multicolumn{2}{|c|}{ Dual histamine challenge II } & \multicolumn{2}{|c|}{ Histamine challenge after exercise } \\
\hline & Baseline $F E V_{1}(l)$ & $P C_{20}(\mathrm{mg} / \mathrm{ml})$ & Baseline $F E V_{1}(l)$ & $P C_{20}(\mathrm{mg} / \mathrm{ml})$ & Baseline $F E V_{1}(l)$ & $P C_{20}(\mathrm{mg} / \mathrm{ml})$ \\
\hline $\begin{array}{l}1 \\
2 \\
3 \\
4 \\
5 \\
6 \\
7 \\
8 \\
\text { Mean } \\
\text { (SD) } \\
\text { Geometric mean }\end{array}$ & $\begin{array}{c}1 \cdot 86 \\
2 \cdot 10 \\
2 \cdot 50 \\
2 \cdot 40 \\
2 \cdot 32 \\
3 \cdot 21 \\
2 \cdot 37 \\
3 \cdot 25 \\
2 \cdot 50 \\
(0 \cdot 49)\end{array}$ & $\begin{array}{l}8 \cdot 17 \\
1 \cdot 22 \\
1 \cdot 12 \\
3 \cdot 16 \\
2 \cdot 32 \\
0 \cdot 22 \\
0 \cdot 83 \\
1 \cdot 97 \\
\\
1 \cdot 53\end{array}$ & $\begin{array}{l}1.98 \\
2 \cdot 08 \\
1.75 \\
2 \cdot 20 \\
2.47 \\
2 \cdot 81 \\
2 \cdot 25 \\
3 \cdot 10 \\
2 \cdot 33 \\
(0 \cdot 44)\end{array}$ & $\begin{array}{l}2.80 \\
0.46 \\
5.47 \\
0.82 \\
0.82 \\
0.35 \\
0.07 \\
4.86 \\
\\
\\
0.93\end{array}$ & $\begin{array}{l}1.31 \\
1.65 \\
1.86 \\
1.30 \\
2.57 \\
2.60 \\
2.49 \\
2.34 \\
2.02 \\
(0.55)\end{array}$ & $\begin{array}{l}7 \cdot 39 \\
1 \cdot 08 \\
1 \cdot 72 \\
0 \cdot 24 \\
0.76 \\
0.41 \\
2 \cdot 27 \\
6 \cdot 36 \\
\\
\\
1.40\end{array}$ \\
\hline
\end{tabular}




\section{Discussion}

Previous research has indicated clearly that there are some asthmatic patients who do not show refractoriness after exercise induced asthma. ${ }^{14}$ The eight subjects in the present study were selected on the basis of their refractory responses to the paired exercise challenge. This refractoriness was apparently not due to increased tolerance of airway smooth muscle resulting simply from the effects of repeated exposure to histamine as successive challenges with exogenous histamine produced no overall diminution in pulmonary responsiveness. This finding contradicts the work of Schoeffel et al, who reported a significant reduction in bronchial hyperreactivity to histamine with repeated challenges. ${ }^{4}$ They, however, administered histamine in progressively increasing concentrations in the case of the initial challenge and as a single large dose in subsequent trials. The actual histamine concentrations in the airways may therefore have differed between challenges. In our study histamine was always administered in gradually increasing dosage. Furthermore, Schoeffel et al allowed a clear interval of 40 minutes between successive histamine trials. ${ }^{4} \mathrm{We}$ allowed an interval of this duration between the starts of the two challenges so that the period between the end of the first challenge and the beginning of the second was about 30 minutes. This earlier rechallenge may have limited opportunity for repolarisation of airway smooth muscle cells.

It is conceivable that persistence of catecholamines after exercise could produce changes in airway smooth muscle that might protect from the influence of subsequent mediator exposure. ${ }^{5}$ The available evidence indicates, however, that plasma adrenaline concentration either does not rise in asthmatic patients in response to exercise ${ }^{10}$ or shows a rapid return to resting concentrations after stopping exercise." Furthermore, if the effects of catecholamines did persist, reduced histamine sensitivity might be expected during the refractory period, but this was not seen. The question arises of whether the unchanged $\mathrm{PC}_{20}$ in the presence of a significantly reduced baseline $\mathrm{FEV}_{1}$ (table 2 ) indicates a real decrease in histamine reactivity. The crucial comparison in the present context concerns the exercise and histamine provocations carried out during the refractory period after initial exercise challenge. The mean baseline $\mathrm{FEV}_{1}$ scores for these provocations were very similar. The histamine challenge produced a percentage fall in $\mathrm{FEV}_{1}$ similar to that seen under control conditions, whereas the exercise challenge (by definition) did not. These findings indicate that during the period of diminished sensitivity to exercise there is no equiv- alent change in responsiveness to histamine. The suggestion that refractoriness is due to persistence of bronchodilating catecholamines after initial exercise $^{s}$ is therefore not supported.

The refractory period after exercise induced asthma has been widely ascribed to depletion of mediators stored in airway mast cells. ${ }^{2-4}$ The duration of the refractory period is believed to correspond to the time required for complete mediator resynthesis. ${ }^{3}$ This view is supported by evidence clearly suggesting mast cell roles in at least a substantial proportion of cases of exercise induced asthma. Lee et al reported increased plasma concentrations of neutrophil chemotactic factor in association with development of exercise induced asthma and also showed that no such increase occurs in response to exercise performed with warm humid inspirate to prevent asthmatic attack. ${ }^{12}$ Anderson et al have observed raised arterial histamine concentrations during acute exacerbations of asthma provoked by exertion. ${ }^{13}$ Pre-exercise inhalation of disodium cromoglycate, a substance capable of inhibiting mast cell degranulation, can prevent or ameliorate exercise induced asthma in most patients. ${ }^{1415} \mathrm{~A}$ similar finding has been reported with $\mathrm{H}_{1}$ receptor antagonists. ${ }^{16}$

Our data are compatible with the theory of mediator depletion. Reduced percentage fall in $\mathrm{FEV}_{1}$ with exercise at a time of unchanged $\mathrm{PC}_{20}$ for histamine certainly suggests the possibility of considerably decreased mediator release. The extent of mediator depletion that would be necessary to explain this result is debatable. In the early stages of exercise asthmatic patients typically bronchodilate. ${ }^{17}$ In the second of the paired exercise tests the initial bronchodilating influence may have caused rapid repolarisation of airway smooth muscle after initial exercise induced asthma. Accordingly, the underlying state of airways at the time of mediator release in the second test may have been better than suggested by the pre-exercise $\mathrm{FEV}_{1}$. Use of the pre-exercise reading as a baseline for calculating maximum reduction in $\mathrm{FEV}_{1}$ may therefore have led to overestimation of the degree of refractoriness displayed by our subjects.

Arguments against mediator depletion as the mechanism of refractoriness are based partly on the report of Ben-Dov et al that exercise with hot humid inspirate (which produces little or no asthma) is often followed by a refractory period. ${ }^{18}$ This report, however, is in conflict with the findings of Anderson et $a l^{19}$ and with unpublished data from our laboratory. Repeated brief treadmill runs can cause refractoriness without provoking asthma, ${ }^{20}$ but this may be due to release of mediators over an extended period at a rate insufficient to affect airways calibre. We 
believe that, on the current evidence, mediator depletion remains the most likely explanation for the refractory period after exercise induced asthma.

This study was supported by a grant from the Menzies Foundation, East Melbourne, Victoria, Australia. The researchers are grateful also to $\mathrm{Dr}$ Sandra Anderson for her advice on aspects of experimental design and for helpful comments regarding the manuscript.

\section{References}

1 McNeill RS, Nairn JR, Millar JS, Ingram CG. Exercise-induced asthma. $Q J$ Med 1966;35:55-67.

2 James L, Faciane J, Sly RM. Effect of treadmill exercise on asthmatic children. J Allergy Clin Immunol 1976;57:409-16.

3 Edmunds AT, Tooley M, Godfrey S. The refractory period after exercise-induced asthma: its duration and relation to the severity of exercise. Am Rev Respir Dis 1978; 117:247-54.

4 Schoeffel RE, Anderson SD, Gillam I, Lindsay DA. Multiple exercise and histamine challenge in asthmatic patients. Thorax 1980;35:164-70.

5 Stearns DR, McFadden ER, Breslin FJ, Ingram RH. Reanalysis of the refractory period in exertional asthma. J Appl Physiol 1981;50:503-8.

6 deVries H. Physiology of exercise for physical education and athletics. Iowa: WC Brown, 1974.

7 List RJ. Smithsonian meteorological tables 1949. 6th ed. Washington: Smithsonian Institute Press, 1949. (Smithsonian miscellaneous collections Vol 114.)

8 Deal EC, McFadden ER, Ingram RH, Strauss RH, Jaeger JJ. Role of respiratory heat exchange in production of exercise-induced asthma. J Appl Physiol 1979; 46:467-75

9 Silverman M, Anderson SD. Standardization of exer- cise tests in asthmatic children. Arch Dis Child 1972;47:882-9.

10 Barnes PJ, Brown MJ, Silverman M, Dollery CT. Circulating catecholamines in exercise and hyperventilation induced asthma. Thorax 1981;36:435-40.

11 Zielinski J, Chodosowska E, Radomyski A, Araszkiewicz Z, Kozlowski S. Plasma catecholamines during exercise-induced bronchoconstriction in bronchial asthma. Thorax 1980;35:823-7.

12 Lee TH, Assouf BK, Kay AB. The link between exercise, respiratory heat exchange and the mast cell in bronchial asthma. Lancet 1983;i:520-2.

13 Anderson SD, Bye PTP, Schoeffel RE, Seale JP, Taylor KM, Ferris L. Arterial plasma histamine levels at rest and during and after exercise in patients with asthma: effects of terbutaline aerosol. Thorax 1981;36:259-67.

14 Morton AR, Fitch KD. Sodium cromoglycate BP in the prevention of exercise-induced asthma. Med J Aust $1974 ; 2: 158-62$.

15 Wallace D, Grieco MH. Double-blind crossover study of cromolyn sodium inhibition of exercise-induced bronchospasm in adults. Ann Allergy 1976;37:153-63.

16 Hartley JPR, Nogrady SG. Effect of an inhaled antihistamine on exercise-induced asthma. Thorax 1980;35:675-9.

17 Jones RS, Wharton MJ, Buston MH. The place of physical exercise and bronchodilator drugs in the assessment of the asthmatic child. Arch Dis Child 1963;38:539-45.

18 Ben-Dov I, Bar-Yishay E, Godfrey S. Refractory period after exercise-induced asthma unexplained by respiratory heat loss. Am Rev Respir Dis 1982; 125: $530-4$.

19 Anderson SD, Daviskas E, Schoeffel RE, Unger SF Prevention of severe exercise-induced asthma with hot humid air. Lancet 1979;ii: 629.

20 Schnall RP, Landau LI. Protective effects of repeated short sprints in exercise-induced asthma. Thorax 1980;35:828-32. 